ARTICLE

\title{
Coordination modulation of iridium single-atom catalyst maximizing water oxidation activity
}

\author{
Zhanwu Lei ${ }^{1,5}$, Wenbin Cai ${ }^{1,5}$, Yifei Rao ${ }^{1,5}$, Kuan Wang ${ }^{2}$, Yuyuan Jiang ${ }^{2}$, Yang Liu' ${ }^{1}$ Xu Jin ${ }^{3}$, Jianming Li ${ }^{3}$, \\ Zhengxing $\mathrm{Lv}^{4}$, Shuhong Jiao (1) ${ }^{1 \times}$, Wenhua Zhang (i] ${ }^{1 \times}$, Pengfei Yan $\mathbb{D}^{2}{ }^{2}$, Shuo Zhang ${ }^{4}$ \& Ruiguo Cao (i) ${ }^{1 \times}$
}

Single-atom catalysts (SACs) have attracted tremendous research interests in various energy-related fields because of their high activity, selectivity and $100 \%$ atom utilization. However, it is still a challenge to enhance the intrinsic and specific activity of SACs. Herein, we present an approach to fabricate a high surface distribution density of iridium (Ir) SAC on nickel-iron sulfide nanosheet arrays substrate ( $\left(\mathrm{r}_{1} / \mathrm{NFS}\right)$, which delivers a high water oxidation activity. The $\mathrm{Ir}_{1} / \mathrm{NFS}$ catalyst offers a low overpotential of $\sim 170 \mathrm{mV}$ at a current density of $10 \mathrm{~mA} \mathrm{~cm}^{-2}$ and a high turnover frequency of $9.85 \mathrm{~s}^{-1}$ at an overpotential of $300 \mathrm{mV}$ in $1.0 \mathrm{M} \mathrm{KOH}$ solution. At the same time, the $\mathrm{Ir}_{1} / \mathrm{NFS}$ catalyst exhibits a high stability performance, reaching a lifespan up to 350 hours at a current density of $100 \mathrm{~mA} \mathrm{~cm}{ }^{-2}$. Firstprinciples calculations reveal that the electronic structures of $\mathrm{Ir}$ atoms are significantly regulated by the sulfide substrate, endowing an energetically favorable reaction pathway. This work represents a promising strategy to fabricate high surface distribution density single-atom catalysts with high activity and durability for electrochemical water splitting.

\footnotetext{
${ }^{1}$ Hefei National Laboratory for Physical Sciences at the Microscale, CAS Key Laboratory of Materials for Energy Conversion, Department of Materials Science and Engineering, University of Science and Technology of China, Hefei, Anhui 230026, China. ${ }^{2}$ Beijing Key Laboratory of Microstructure and Properties of Solids, Beijing University of Technology, Beijing 100124, China. ${ }^{3}$ Research Center of New Energy, Research Institute of Petroleum Exploration and Development (RIPED), PetroChina, Beijing 100083, China. ${ }^{4}$ Shanghai Synchrotron Radiation Facility, Shanghai Institute of Applied Physics, Chinese Academy of Sciences, Shanghai 201204, China. ${ }^{5}$ These authors contributed equally: Zhanwu Lei, Wenbin Cai, Yifei Rao. ${ }^{凶}$ email: jiaosh@ustc.edu.cn; whhzhang@ustc.edu.cn; rgcao@ustc.edu.cn
} 
E lectrochemical water splitting is considered as a sustainable option for large-scale hydrogen production by using renewable energy, such as solar, wind and hydropower ${ }^{1-3}$. However, the sluggish kinetics of water electrolysis results in high overpotentials for both hydrogen evolution reaction (HER) and oxygen evolution reaction (OER $)^{4,5}$, thus significantly sacrificing the energy efficiency and increasing the hydrogen production $\operatorname{cost}^{6,7}$. Especially, the OER reaction involves a four-electron process which suffers from ten times higher overpotentials than that of HER, making it a bottleneck process in the overall water electrolysis system ${ }^{4,8}$. The commercial electrocatalysts used for water oxidaton in alkaline electrolyzer are Ni-based catalysts ${ }^{9}$. However, their catalytic performance remains far from satisfactory for the cost competiveness of hydrogen production. Thus, tremendous efforts have been made to improve the OER performance ${ }^{10}$, thus achieving high-efficiency electrolysis for cost-effective hydrogen energy in alkaline electrolyzer. So far, the catalysts for OER need to utilize precious metals, such as iridium (Ir) and ruthenium $(\mathrm{Ru})$, to suppress the overpential during the water electrolysis process ${ }^{11}$. The utilization of precious metal catalysts significantly impairs the cost competitiveness of hydrogen production via electrochemical water splitting in comparison with other conventional hydrogen production technologies from the steam reforming process ${ }^{12}$, thus hindering the wide deployment of the electrolytic hydrogen production technology in the future ${ }^{13-15}$.

Single-atom catalysts (SACs) provide a promising option to significantly reduce the utilization amount of precious metal catalysts by maximizing the atom-efficiency of precious metal elements in catalyst materials ${ }^{16-21}$. Recently, tremendous efforts have been devoted to developing efficient SACs for suppressing the OER overpotentials and improving the reaction kinetics for electrochemical water splitting ${ }^{22-25}$. It has been proved that the utilization of SACs could significantly improve the intrinsic activity of precious metal elements for the OER process and result in high mass activity $24,26,27$. The interaction between individual precious metal atoms and support substrate plays essential roles in modulating the microenvironment of active sites and consequently improves their activity and durability ${ }^{28-30}$. Various substrate materials have been attempted to maximize the mass activity of previous metals ${ }^{31-35}$. Despite these endeavors in developing suitable substrates for OER catalysts ${ }^{17,36,37}$, the fundamental understanding of the interaction between the substrate and the supported isolated atoms is still illusive $e^{38-40}$. Another major challenge in the fundamental science of SACs is to enhance the surface distribution density of active sites on the outer surface of substrates, rather than embedded inside the bulk materials ${ }^{28,38}$.

Herein, we report a facile and scalable strategy to fabricate a low mass loading but high surface distribution density Ir SAC by anchoring on the $\mathrm{Ni}_{(3-\mathrm{x})} \mathrm{Fe}_{\mathrm{x}} \mathrm{S}_{2}\left(\mathrm{Ir}_{1} / \mathrm{NFS}\right)$ nanosheet arrays via a two-step electrochemical method. The separation of substrate construction and Ir SAC deposition makes the distribution of Ir atoms only on the surface of the substrate, rather than inside the electrode, therefore maximizing the utilization of precious metals. As a result, the $\operatorname{Ir}_{1} / \mathrm{NFS}$ exhibits a high OER catalytic performance, which delivers an ultra-low overpotential of $\sim 170 \mathrm{mV}$ at a current density of $10 \mathrm{~mA} \mathrm{~cm}^{-2}$ with an ultra-high turnover frequency (TOF) of $9.85 \mathrm{~s}^{-1}$ at an overpotential of $300 \mathrm{mV}$. Density functional theory (DFT) calculations predict that the suitable chemical environment of Ir single-atom on the surface of NFS by Ir-S-M bond ( $\mathrm{M}$ stands for $\mathrm{Ni}$ or $\mathrm{Fe}$ ) efficiently reduces the kinetic energy barrier to form ${ }^{*} \mathrm{OOH}$ group from ${ }^{*} \mathrm{O}$ group, and thus accelerates the OER process.

\section{Results}

Catalysts fabrication and characterization. The fabrication process of $\mathrm{Ir}_{1} / \mathrm{NFS}$ on a Ni foam electrode is illustrated in Fig. 1a. In order to separate the substrate construction and Ir SAC a

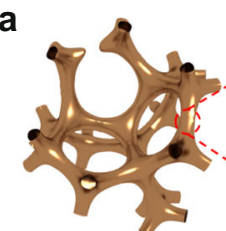

Ni foam

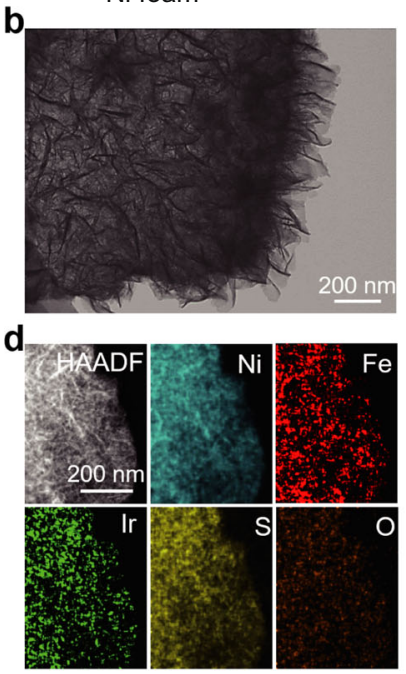

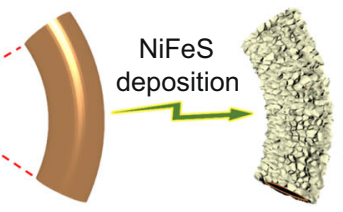

$\mathrm{NiFeS/Ni} \mathrm{foam}$

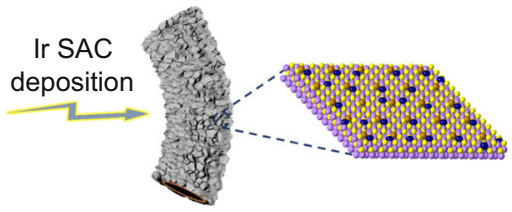

IrVNiFeS/Ni foam

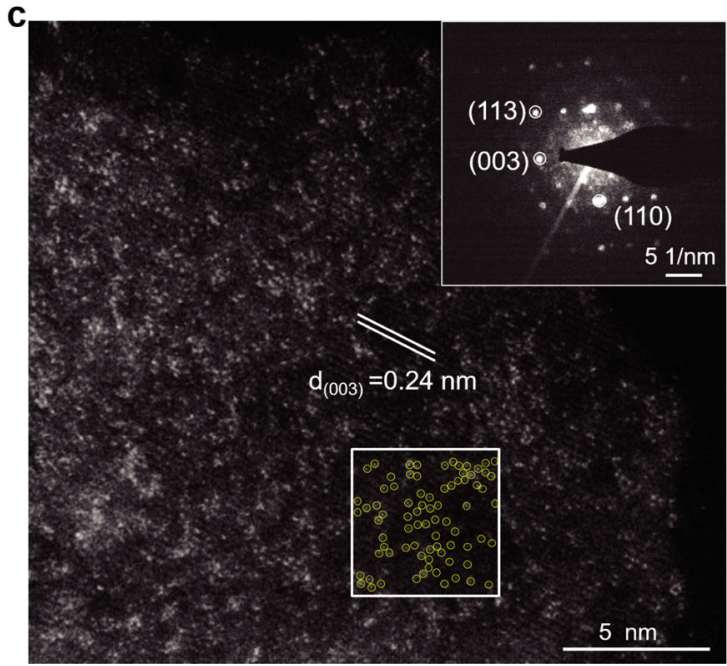

Fig. 1 Electron microscope analysis of the $\mathbf{I r}_{1}$ /NFS. a Schematic illustration of the deposition to form the $\operatorname{lr}_{1} / \mathrm{NFS}$ with two-step method. $\mathbf{b}$ TEM image of as-prepared the $\operatorname{Ir}_{1} / \mathrm{NFS}$. Scale bar, $200 \mathrm{~nm}$. c HAADF-STEM image of the $1 \mathrm{r}_{1} / \mathrm{NFS}$ (inset: SAED pattern) and the high density bright dots highlighted by yellow circles in an area of $5 \mathrm{~nm} \times 5 \mathrm{~nm}$. Scale bar, $5 \mathrm{~nm}$. d HAADF image and the corresponding EDX elemental mappings of Ni, Fe, Ir, S, and O. Scale bar, $200 \mathrm{~nm}$. 
deposition processes, the nickel-iron sulfide nanosheets were firstly deposited on a $\mathrm{Ni}$ foam electrode by sweeping the potentials between $0.2 \mathrm{~V}$ and $-1.2 \mathrm{~V}$ versus $\mathrm{Hg} / \mathrm{HgO}$ reference electrode in a solution containing thiourea (TU) and nickel-iron precursors. Subsequently, the iridium precursor was added into the electrolyte and the electrode was swept between $0.3 \mathrm{~V}$ and $-0.3 \mathrm{~V}$ versus $\mathrm{Hg} / \mathrm{HgO}$ reference electrode for Ir single-atoms deposition (see details in experimental methods). As a result, the Ir atoms were deposited on the surface of NFS substrate, rather than inside the electrode, therefore maximizing the utilization of Ir atoms. Notably, thiourea plays an essential role in forming the sulfide substrate during the first deposition step and stabilizing the Ir precursor in the electrolyte during the second deposition step. Raman spectra shows a negative shift $\left(\sim 10 \mathrm{~cm}^{-1}\right)$ for the peak at $489 \mathrm{~cm}^{-1}$ with increasing thiourea concentration (Supplementary Fig. 1), indicating that Ir ions form the complex of $\operatorname{Ir}(\mathrm{TU})_{\mathrm{x}}$ in the electrolyte ${ }^{41}$. The formation of complex ions prevents the formation of Ir clusters and nanoparticles during the deposition process. When without adding thiourea in the electrolyte, the Ir SAC on nickel-iron hydroxide substrate $\left(\operatorname{Ir}_{1} / \mathrm{NFH}\right)$ was formed after the same deposition procedure.

The scanning electron microscopy (SEM) characterization results reveal that the $\operatorname{Ir}_{1} / \mathrm{NFS}$ catalyst displays a highly porous surface morphology with interconnected wrinkles (Supplementary Fig. 2), which is helpful to expose high surface area and render more active sites. The corresponding transmission electron microscope (TEM) image further confirms that the $\mathrm{Ir}_{1} /$ NFS nanosheets are composed of a fluffy ultrathin layered structure (Fig. 1b). The high-angle annular dark field-scanning transmission electron microscopy (HAADF-STEM) image reveals that the high-density isolated Ir atoms are homogeneously dispersed on the surface of NFS, without showing any aggregated clusters and nanoparticles (Fig. 1c, and Supplementary Fig. 3). The intensity line profile confirms that the Ir atom is located on the surface of NFS (Supplementary Fig. 4) ${ }^{31}$. Significantly, as shown in the framed area of Fig. 1c, the surface distribution density of $\mathrm{Ir}_{1}$ atoms reaches up to $\sim 3$ atoms per square nanometer, which is higher than most of ever-reported SACs in literatures ${ }^{16,17,23}$. As shown in the inset of Fig. 1c, the selected area electron diffraction (SAED) pattern presents the diffraction spots for (110), (113), and (003) planes from a hexagonal structure of NFS nanosheets. The elemental mapping results based on the energy-dispersive X-ray (EDX) further prove that the Ir element is uniformly distributed on the NFS nanosheets in a large scale area without showing any aggregation phenomena (Fig. 1d). Notably, the mass content of $\mathrm{Ir}$ in $\mathrm{Ir}_{1} / \mathrm{NFS}$ is determined to be $\sim 0.6 \mathrm{wt} \%$ by the inductively coupled plasma mass spectrometry (ICP-MS) measurement.

For comparison, the morphology and structure of $\operatorname{Ir}_{1} / \mathrm{NFH}$ were also characterized by using SEM and TEM. The electrode with $\mathrm{Ir}_{1} / \mathrm{NFH}$ also shows porous surface morphology similar to the electrode with $\operatorname{Ir}_{1} / \mathrm{NFS}$ (Supplementary Fig. 5). However, the $\mathrm{Ir}_{1} / \mathrm{NFH}$ catalyst possesses thicker nanosheets in comparison to the $\operatorname{Ir}_{1} / \mathrm{NFS}$ catalyst (Supplementary Fig. 6). The HAADF-STEM images reveal that the isolated Ir atoms are distributed on the $\mathrm{NFH}$ nanosheets, showing less aggregated Ir clusters (Supplementary Figs. 7 and 8). Furthermore, the corresponding EDX elemental mappings also show a homogeneous Ir distribution in the $\mathrm{Ir}_{1} / \mathrm{NFH}$ catalyst (Supplementary Fig. 9). Notably, the Ir mass loadings in $\mathrm{Ir}_{1} / \mathrm{NFH}$ is $\sim 0.54 \mathrm{wt} \%$ by ICP-MS measurement, which is very close to the $\operatorname{Ir}$ loading in $\operatorname{Ir}_{1} /$ NFS. Based on these characterization results, it indicates that the sulfide substrate is more favorable for forming high surface distribution density Ir single-atom in comparison with the hydroxide substrate. In order to prove this hypothesis, various precious metal SACs on NFS were fabricated following the same synthesis procedure, including
$\mathrm{Ru}_{1} / \mathrm{NFS}, \mathrm{Au}_{1} / \mathrm{NFS}$, and $\mathrm{Pt}_{1} / \mathrm{NFS}$ (Supplementary Figs. 10-12). The isolated $\mathrm{Pt}_{1}, \mathrm{Au}_{1}$, and $\mathrm{Ru}_{1}$ can be homogeneously dispersed on the surface of NFS, without showing any aggregated clusters and nanoparticles (Supplementary Figs. 13-15).

The X-ray diffraction (XRD) patterns reveal that both $\mathrm{Ir}_{1} / \mathrm{NFS}$ and NFS possess the same crystalline structure that can be assigned to a crystal phase (PDF\# 44-1418) of $\mathrm{Ni}_{3} \mathrm{~S}_{2}$ (Fig. $2 \mathrm{a}$ and Supplementary Fig. 16), indicating that the electrochemical process for Ir SAC deposition does not change the structure of NFS substrate. In contrast, the XRD patterns of both $\operatorname{Ir}_{1} / \mathrm{NFH}$ and $\mathrm{NFH}$ show less crystalline structure with two broad peaks at $35^{\circ}$ and $62^{\circ}$, which can be assigned to a crystalline structure of $\mathrm{Ni}(\mathrm{OH})_{2} \cdot 0.75 \cdot \mathrm{H}_{2} \mathrm{O}$ (PDF\# 038-0715). X-ray photoelectron spectroscopy (XPS) was conducted to investigate the valence states of different elements in the catalysts. The core level Ir $4 f$ spectra of $\operatorname{Ir}_{1} / \mathrm{NFS}$ shows two peaks at $66.0 \mathrm{eV}\left(\operatorname{Ir} 4 f_{5 / 2}\right)$ and $62.9 \mathrm{eV}\left(\operatorname{Ir} 4 f_{7 / 2}\right)$, respectively. For comparison, the corresponding binding energy of Ir for $\operatorname{Ir}_{1} / \mathrm{NFS}$ is slightly lower than that for $\operatorname{Ir}_{1} / \mathrm{NFH}(63.2 \mathrm{eV}$ for Ir $\left.4 f_{7 / 2}\right)$, confirming the weaker chemical interaction in $\operatorname{Ir}_{1} / \mathrm{NFS}$ than that in $\operatorname{Ir}_{1} / \mathrm{NFH}$ (Fig. 2b). To further investigate the valence state of Ir, the XPS measurements for $\mathrm{IrCl}_{3} \cdot \mathrm{xH}_{2} \mathrm{O}$ and $\mathrm{IrO}_{2}$ were performed as references. It is observed that the valence state of Ir single-atoms in $\operatorname{Ir}_{1} / \mathrm{NFS}$ is slightly below the Ir (III) species in $\mathrm{IrCl}_{3} \cdot \mathrm{xH}_{2} \mathrm{O}$, and is much lower than the $\mathrm{Ir}$ (IV) species in $\mathrm{IrO}_{2}$ (Supplementary Figs. 17 and 18). XPS depth profiling spectra of $\mathrm{Ir}^{3+} 4 f$ show that the peak intensity of $\operatorname{Ir}^{3+} 4 f$ decreases along with the increase of sputtering time while the peak intensity of $\mathrm{Ni}^{2+} 3 p$ has no obvious change, which indicates that the Ir SACs are located on the surface of NFS nanosheets (Supplementary Fig. 19). In addition, the high-resolution XPS $S 2 p$ spectrum implies the formation of Ir-S-M (M stands for Ni or Fe) bond in $\mathrm{Ir}_{1} / \mathrm{NFS}$, further confirming the charge transfer from Ir atoms to the substrate (Fig. 2c). Notably, $\mathrm{SO}_{\mathrm{x}}{ }^{2-}$ species are observed in the $\mathrm{S} 2 p$ spectra, indicating that the surface sulfur element is oxidized to some extent. The $\mathrm{Ni}^{2+} 2 p$ and $\mathrm{Fe}^{3+} 2 p$ XPS spectra of $\mathrm{Ir}_{1} / \mathrm{NFS}$ have no shift compared with that in NFS (Figs. 2d, e). Moreover, we further studied the charge transfer between other SACs and the sulfide substrate, including $\mathrm{Ru}_{1} / \mathrm{NFS}, \mathrm{Au}_{1} / \mathrm{NFS}$, and $\mathrm{Pt}_{1} / \mathrm{NFS}$. It is observed that the valence states of $\mathrm{Ru}, \mathrm{Au}$, and $\mathrm{Pt}$ in $\mathrm{Ru}_{1} / \mathrm{NFS}$, $\mathrm{Au}_{1} / \mathrm{NFS}$, and $\mathrm{Pt}_{1} / \mathrm{NFS}$ are $\mathrm{Ru}^{3+}\left[463.3 \mathrm{eV}\left(4 f_{7 / 2}\right)\right], \mathrm{Au}^{3+}[83.9 \mathrm{eV}$ $\left.\left(4 f_{7 / 2}\right)\right]$, and $\mathrm{Pt}^{4+}\left[72.8 \mathrm{eV}\left(4 f_{7 / 2}\right)\right]$ based on the XPS spectra (Supplementary Figs. 20-22), suggesting that the charge transfer also exist between various precious metal atoms and the NFS substrate.

Electrochemical oxygen evolution performance. The electrocatalytic performances of the $\operatorname{Ir}_{1} / \mathrm{NFS}$ for OER were evaluated in 1.0 M KOH solution. All potentials were calibrated with respect to the reversible hydrogen electrode (RHE) (Supplementary Fig. 23). The commercial $\mathrm{Ir} / \mathrm{C}(5 \mathrm{wt} \%)$ and $\mathrm{IrO}_{2}$ catalysts were also tested as a benchmark value for OER activity. Remarkably, the OER overpotential for $\operatorname{Ir}_{1} / \mathrm{NFS}$ is observed down to $\sim 170 \mathrm{mV}$ for reaching a current density of $10 \mathrm{~mA} \mathrm{~cm}^{-2}$, which is much lower than $\operatorname{Ir}_{1} / \mathrm{NFH}(\sim 190 \mathrm{mV})$ and also the benchmark catalysts (Fig. $3 \mathrm{a}$ and Supplementary Table 1). Under more practical conditions, the OER overpotentials for $\operatorname{Ir}_{1} / \mathrm{NFS}$ are only 206 and $220 \mathrm{mV}$ at current densities of 100 and $500 \mathrm{~mA} \mathrm{~cm}^{-2}$, respectively. In contrast, the $\mathrm{Ir}_{1} / \mathrm{NFH}$ demonstrates much higher overpotentials of 234 and $257 \mathrm{mV}$, respectively. We furthe investigated the substrate effect on the OER activity of Ir SAC by changing the ratio of $\mathrm{Ni} / \mathrm{Fe}$ in the sulfide substrate (Supplementary Table 2). As shown in Supplementary Fig. 24, the $\operatorname{Ir}_{1} / \mathrm{Ni}_{\mathrm{y}} \mathrm{Fe}_{(6-\mathrm{y})} \mathrm{S}_{\mathrm{x}}(\mathrm{y}=0-6)$ electrodes have similar morphologies showing porous structures with interconnected wrinkles. The electrocatalytic activity of the $\mathrm{Ni}_{\mathrm{y}} \mathrm{Fe}_{(6-\mathrm{y})} \mathrm{S}_{\mathrm{x}}(\mathrm{y}=0-6)$ substrate shows obvious $\mathrm{Ni} / \mathrm{Fe}$ ratio 

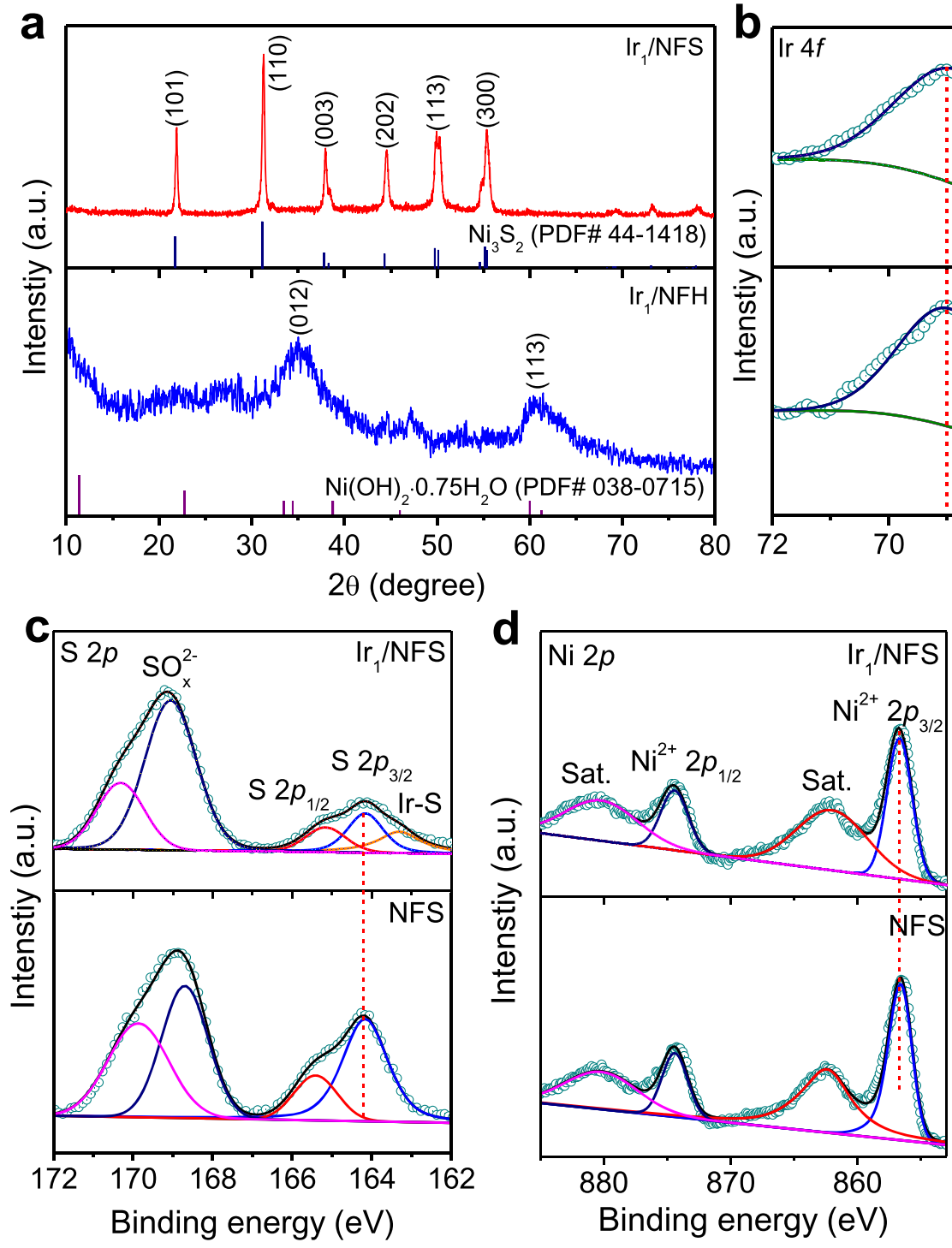

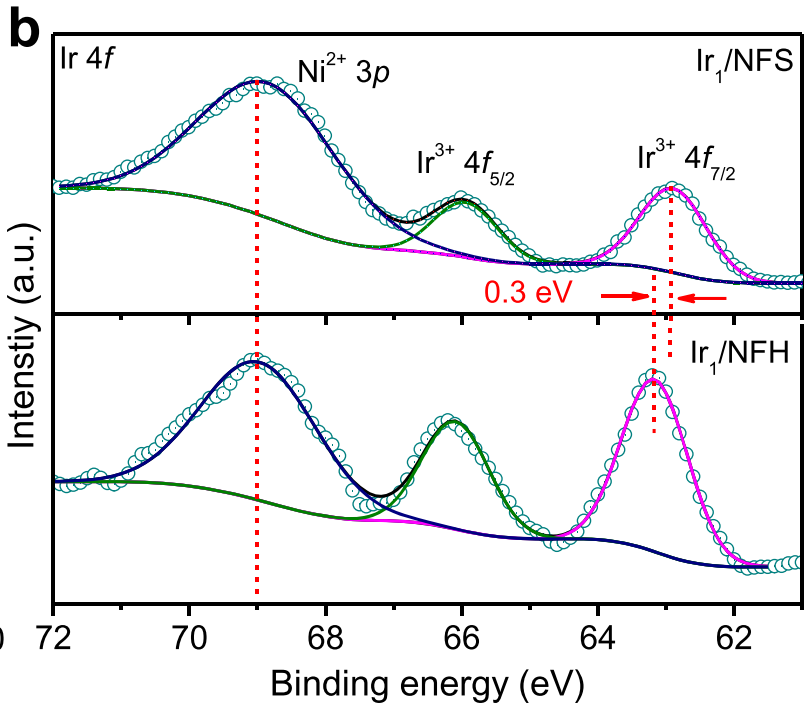

Binding energy $(\mathrm{eV})$

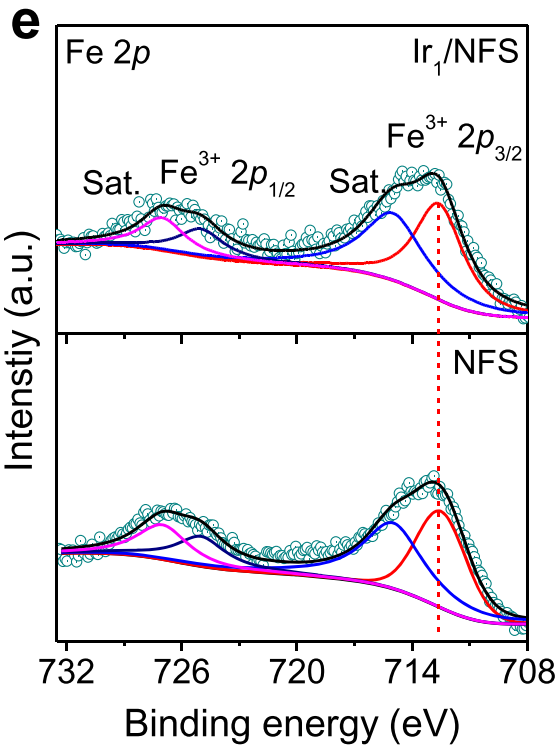

Fig. 2 Physicochemical property characterization. a XRD pattern of the $\operatorname{Ir}_{1} / \mathrm{NFS}$ and $\operatorname{Ir}_{1} / \mathrm{NFH}$. $\mathbf{b}$ XPS spectra of $\operatorname{Ir} 4 f$ region with fitting curves for $\operatorname{Ir} 1 / \mathrm{NFS}$ and $\operatorname{Ir}_{1} / \mathrm{NFH}$. c-e XPS spectra of (c) S $2 p$, (d) Ni $2 p$, and (e) Fe $2 p$ regions with fitting curves for $\operatorname{Ir}_{1} / \mathrm{NFS}$ and NFS.

dependence in $1.0 \mathrm{M} \mathrm{KOH}$ solution, among which the $\mathrm{Ni}_{3} \mathrm{Fe}_{3} \mathrm{~S}_{\mathrm{x}}$ exhibits the superior performance (Supplementary Fig. 25). The $\mathrm{Ir}_{1} / \mathrm{NFS}$ catalysts also follow the similar activity trend when changing the Ni/Fe ratio of NFS substrate (Supplementary Figs. 26 and 27). Tafel plots provide further insights into the OER kinetics (Fig. 3b). The $\operatorname{Ir}_{1} / \mathrm{NFS}$ has a very small Tafel slope $\left(33 \mathrm{mV} \mathrm{dec}^{-1}\right)$, which is lower than that of $\operatorname{Ir}_{1} / \mathrm{NFH}\left(35 \mathrm{mV} \mathrm{dec}^{-1}\right)$, $\mathrm{Ir} / \mathrm{C}\left(87 \mathrm{mV} \mathrm{dec}^{-1}\right)$, and $\mathrm{IrO}_{2}\left(95 \mathrm{mV} \mathrm{dec}^{-1}\right)$. The low Tafel slope of $\operatorname{Ir}_{1} / \mathrm{NFS}$ suggests that the NFS substrate could significantly improve the electrochemical kinetics of Ir single-atoms.

In order to exclude the geometric effects on activity assessment, the OER activities of various catalysts were also tested on a flat $\mathrm{Ni}$ film $\left(\mathrm{Ni} / \mathrm{Au}_{\text {disc }}\right)$, which was electrodeposited on a gold disc electrode. $\mathrm{Ir}_{1} / \mathrm{NFS}$ requires an overpotential of $230 \mathrm{mV}$ for reaching a current density of $10 \mathrm{~mA} \mathrm{~cm}{ }^{-2}$ on $\mathrm{Ni} / \mathrm{Au}_{\text {disc }}$ electrode, while $\mathrm{Ir}_{1}$ / $\mathrm{NFH}(258 \mathrm{mV})$ need relatively high overpotential to deliver the same current density (Supplementary Fig. 28). Additionally, the specific activity of $\operatorname{Ir}_{1} / \mathrm{NFS}$ and $\operatorname{Ir}_{1} / \mathrm{NFH}$ were calculated based on the mass of Ir loadings on the $\mathrm{Ni} / \mathrm{Au}_{\text {disc }}$ electrode. The calculated specific activity for $\mathrm{Ir}_{1} / \mathrm{NFS}$ is $20.3 \mathrm{~A} \mathrm{~g} \mathrm{~g}_{\mathrm{Ir}}{ }^{-1}$ at $1.45 \mathrm{~V}$ versus RHE, which is $\sim 1.55$ times higher than that of $\operatorname{Ir}_{1} / \mathrm{NFH}\left(13.1 \mathrm{~A} \mathrm{~g}_{\mathrm{Ir}}{ }^{-1}\right)$. The specific activity of $\operatorname{Ir}_{1} / \mathrm{NFS}$ also outperforms most of the well- developed OER catalysts in literatures (Fig. 3c and Supplementary Table 4). The specific activity and turnover frequency (TOF) offers fundamental insights in evaluating the intrinsic activities of electrocatalysts 7,27 . The TOF was calculated based on the current density at the overpotential of $300 \mathrm{mV}$. The TOF of $\operatorname{Ir}_{1} / \mathrm{NFS}$ reaches up to $9.85 \mathrm{~s}^{-1}$, which is an order of magnitude higher than that of $\mathrm{Ir}_{1} / \mathrm{NFH}\left(1.15 \mathrm{~s}^{-1}\right)$ and previously reported values in literatures (Fig. 3d and Supplementary Table 5).

The electrochemical impedance spectroscopy (EIS) was employed to investigate the charge transfer kinetics on various catalysts at an overpotential of $250 \mathrm{mV}$ on $\mathrm{Ni} / \mathrm{Au}_{\mathrm{disc}}$. Besides the similar resistance of the electrolyte and electrode, the charge transfer resistance $\left(\mathrm{R}_{\mathrm{ct}}\right)$ for $\operatorname{Ir}_{1} / \mathrm{NFS}(\sim 26.5 \Omega)$ is much lower than that for $\operatorname{Ir}_{1} / \mathrm{NFH}(\sim 83.1 \Omega)$ based on the fitted value according to the equivalent circuit (Supplementary Fig. 29 and Supplementary Table 6). Furthermore, the electrochemical double-layer capacitances $\left(\mathrm{C}_{\mathrm{dl}}\right)$ was calculated to evaluate the electrochemically effective surface areas (ECSA) utilized a cyclic voltammetry method $^{42,43}$. It is noted that the $\mathrm{C}_{\mathrm{dl}}$ of $\operatorname{Ir}_{1} / \mathrm{NFS}\left(3.7 \mathrm{mF} \mathrm{cm}^{-2}\right)$ is $\sim 2.0$ times greater than that of the $\operatorname{Ir}_{1} / \mathrm{NFH}\left(1.3 \mathrm{mF} \mathrm{cm}{ }^{-2}\right)$, manifesting that $\operatorname{Ir}_{1} / \mathrm{NFS}$ possesses the most catalytic active sites for OER (Supplementary Fig. 30). 
a

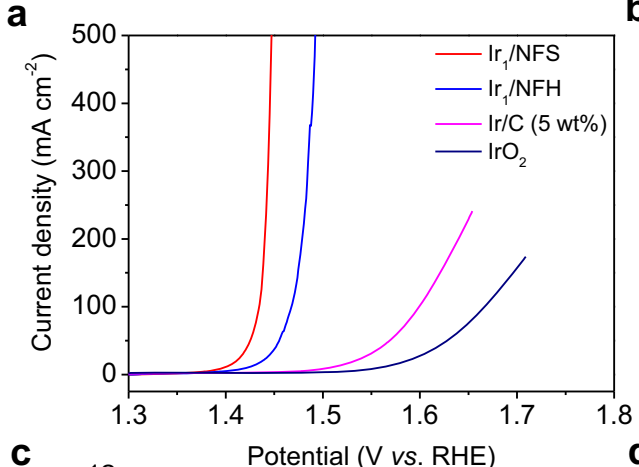

C

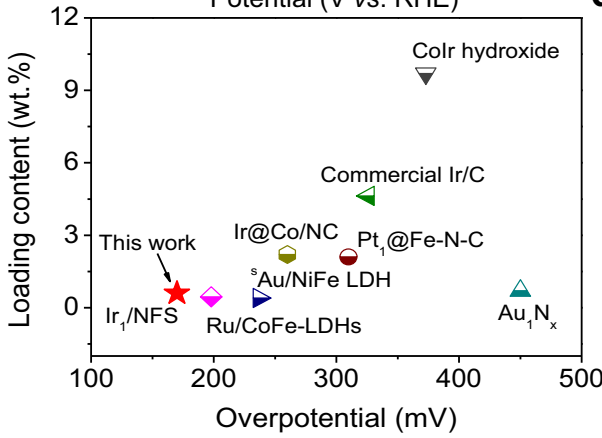

b
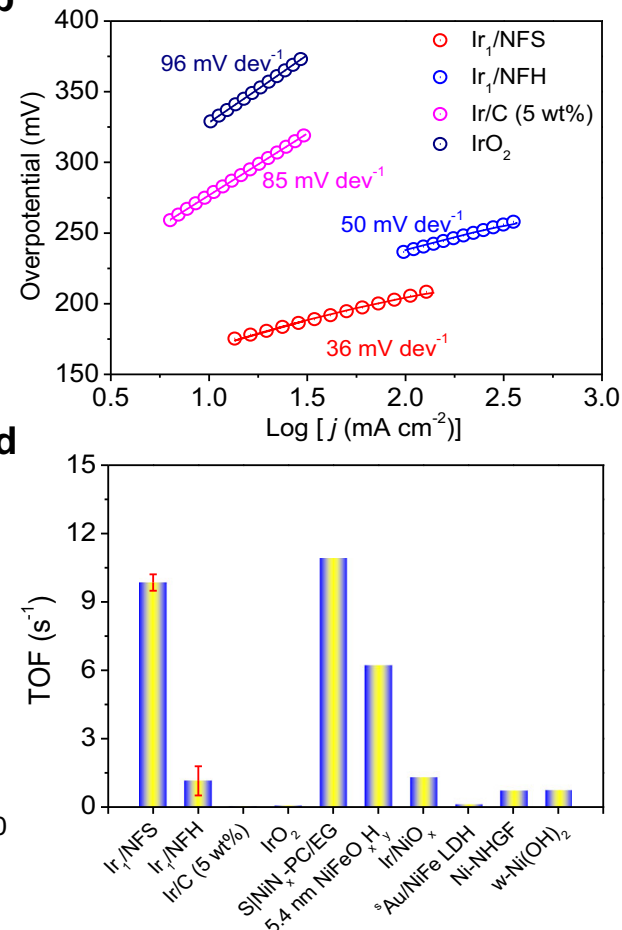

e

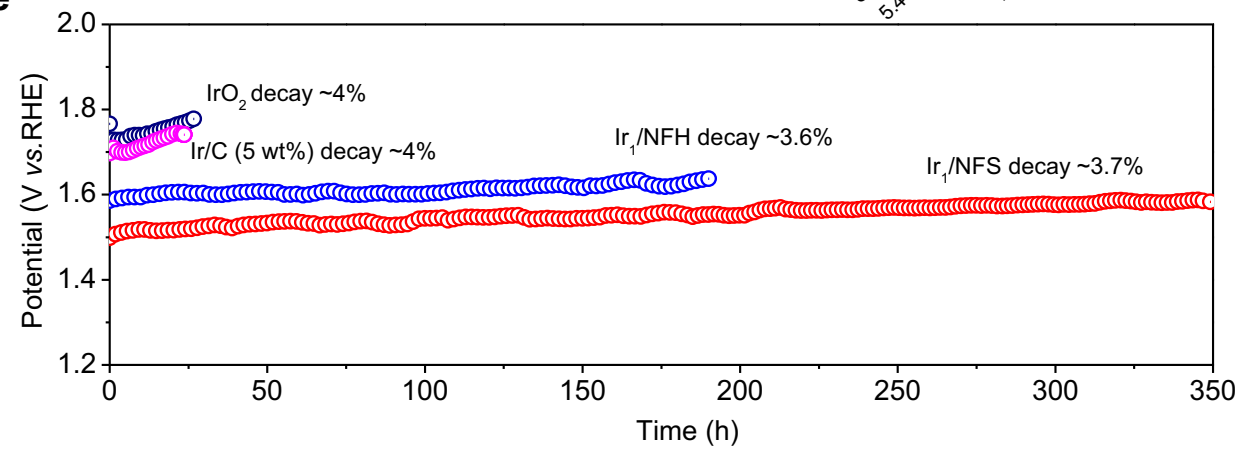

Fig. 3 Electrochemical OER performance. a Polarization curves of $\mathrm{Ir}_{1} / \mathrm{NFS}, \mathrm{Ir} / \mathrm{NFH}, \mathrm{Ir} / \mathrm{C}$ ( 5 wt $\%$ ), and $\operatorname{IrO} \mathrm{O}_{2}$ in $1.0 \mathrm{M} \mathrm{KOH}$. b Tafel plots derived from the polarization curves in (a). c The comparison of overpotentials and precious metal loading contents in reported catalysts at a current density of $10 \mathrm{~mA} \mathrm{~cm}^{-2}$. d The TOFs of state-of-the-art catalysts in alkaline solution (the error bars represent standard deviation values obtained from three independent measurements). e The stability tests of $\mathrm{Ir}_{1} / \mathrm{NFS}, \mathrm{Ir} / \mathrm{NFH}, \mathrm{Ir} / \mathrm{C}(5 \mathrm{wt} \%)$, and $\mathrm{IrO}_{2}$ at $100 \mathrm{~mA} \mathrm{~cm}^{-2}$.

The stability of catalyst is a critical parameter of OER performance, especially for practical applications. The chronoamperometry method was utilized to estimate the stability of $\operatorname{Ir}_{1} /$ NFS and other samples at an overpotential of $250 \mathrm{mV}$ on $\mathrm{Ni}$ foam electrodes. Strikingly, the $\operatorname{Ir}_{1} / \mathrm{NFS}$ displays a relatively higher and more stable current density $\left(\sim 50 \mathrm{~mA} \mathrm{~cm}^{-2}\right)$ than that of $\mathrm{Ir}_{1} / \mathrm{NFH}$ $\left(\sim 27 \mathrm{~mA} \mathrm{~cm}^{-2}\right)$ (Supplementary Fig. 31). Moreover, we evaluated the long-term electrochemical stability by using a chronopotentiometric technique at a relatively high current density of $100 \mathrm{~mA} \mathrm{~cm}^{-2}$. $\mathrm{Ir}_{1} / \mathrm{NFS}$ demonstrates a superior stability performance, showing only $\sim 3.7 \%$ of activity decay after $350 \mathrm{~h}$, which is much better than $\operatorname{Ir}_{1} / \mathrm{NFH}(\sim 3.6 \%$ decay after $198 \mathrm{~h})$, Ir/C (5 wt $\%)(\sim 4 \%$ decay after $25 \mathrm{~h})$ and $\mathrm{IrO}_{2}$ ( 4\% decay after $\left.25 \mathrm{~h}\right)$ (Fig. 3e). To further investigate the leaching effect of the catalyst after a long-term OER test $\left(100 \mathrm{~h}\right.$ at $\left.100 \mathrm{~mA} \mathrm{~cm}{ }^{-2}\right)$, the amounts of dissolution elements from $\mathrm{Ir}_{1} / \mathrm{NFS}$ into the electrolyte was detected by ICP-MS measurement. As shown in Supplementary Fig. 32, the Ir content in electrolyte for $\operatorname{Ir}_{1} / \mathrm{NFS}$ electrode is only $\sim 1 \mathrm{ppb}$, indicating that the $\mathrm{Ir}$ element is stable in the $\mathrm{Ir}_{1} / \mathrm{NFS}$ catalyst during OER test. On the other hand, the $\mathrm{Ni}, \mathrm{Fe}$, and $\mathrm{S}$ content in electrolyte for $\operatorname{Ir}_{1} / \mathrm{NFS}$ electrode is determined to be $\sim 5 \mathrm{ppb}, \sim 13 \mathrm{ppb}$, and $\sim 98 \mathrm{ppb}$, respectively, implying that the substrate transformation corrosion take place during the OER test. To further demonstrate the overall electrochemical water splitting, a large-area $\operatorname{Ir}_{1} /$ NFS electrode $(20 \mathrm{~cm} \times 30 \mathrm{~cm})$ was prepared (Supplementary Fig. 33), which was used to build up a two-electrode electrolysis device for water electrolysis. NiFe-OH$\mathrm{PO}_{4}$ was used as hydrogen evolution catalyst in this device which was synthesized according to the previous literature ${ }^{44}$. As shown in Supplementary Fig. 34, the water electrolysis process could be driven by a single-cell AAA battery with a nominal voltage of $\sim 1.5 \mathrm{~V}$ (Supplementary Movie 1).

In addition, the morphology characterizations of the post-OER $\mathrm{Ir}_{1} / \mathrm{NFS}$ show that the initial nanosheet arrays with interconnected wrinkles are still maintained after testing for $10 \mathrm{~h}$ at an overpotential of $250 \mathrm{mV}$ (Supplementary Fig. 35). The TEM images reveal that the post-OER $\mathrm{Ir}_{1} / \mathrm{NFS}$ nanosheets are composed of a fluffy ultrathin layered structure (Supplementary Fig. 36). The SAED patterns of the post-OER $\operatorname{Ir}_{1}$ /NFS showed two diffraction rings, indicating an amorphous structure transformation after the OER test. The resulting EDX mapping images (Supplementary Fig. 37) show that $\mathrm{Ni}, \mathrm{Fe}, \mathrm{Ir}, \mathrm{S}$, and $\mathrm{O}$ are still homogeneously distributed over the entire post-OER $\operatorname{Ir}_{1}$ /NFS sample. In addition, the HAADF-STEM images exhibit that the monoatomic Ir atoms 
(bright dots) uniform disperse on the surface of substrate and have no obvious aggregated clusters (Supplementary Figs. 38 and 39). Compared with the initial $\mathrm{Ir}_{1} / \mathrm{NFS}$, the crystal structure post-OER $\mathrm{Ir}_{1} / \mathrm{NFS}$ shows a poor crystalline structure, but the main peaks of NFS can be detected as shown in Supplementary Fig. 40. In addition, as shown in the Supplementary Fig. 41, the Ir-S-M (M stands for $\mathrm{Ni}$ or $\mathrm{Fe}$ ) bond is still maintained in the post-OER $\mathrm{Ir}_{1} /$ NFS according to the $S 2 p$ spectrum. It is noted that the binding energy of $\mathrm{Ir}^{3+} 4 f_{7 / 2}$ in post-OER $\mathrm{Ir}_{1} / \mathrm{NFS}$ has a negatively shift $(\sim 0.1 \mathrm{eV})$ compared with that in $\operatorname{Ir}_{1} / \mathrm{NFS}$, indicating the coordination change occur during the OER test. The XPS spectra of $S 2 p$ in post-OER $\operatorname{Ir}_{1} / \mathrm{NFS}$ show that the peak strength ratio of $S^{2-}$ and $\mathrm{SO}_{\mathrm{x}}{ }^{2-}$ displays some predictable changes, implying that the surface sulfur element of NFS is oxidized to some extent ${ }^{45-47}$.

Mechanistic understanding on substrate effect on Ir SAC. To further study the different OER activities on $\mathrm{Ir}_{1} / \mathrm{NFS}$ and $\mathrm{Ir}_{1} / \mathrm{NFH}$ structure models, the spin-polarized density functional theory calculations were employed to simulate the OER process based on the $4 \mathrm{e}^{-}$mechanism proposed by Nørskov (Fig. 4a, b) ${ }^{48,49}$. The Gibbs free energy profiles were calculated to investigate the nature of the activity difference between $\operatorname{Ir}_{1} / \mathrm{NFS}$ and $\operatorname{Ir}_{1} / \mathrm{NFH}$ and the free energy change of each elementary step is listed in Supplementary Table 7. The rate-determining step towards OER for the loaded Ir atom is the conversion of ${ }^{*} \mathrm{O}$ to $* \mathrm{OOH}$ (Fig. 4c, d), consistent with the previous studies under alkaline conditions ${ }^{50,51}$. In comparison with the limiting potential of $1.59 \mathrm{~V}$ versus computed hydrogen electrode (CHE) for $\mathrm{Ir}_{1} / \mathrm{NFH}$ 's rate-determining step, the loaded Ir atom on $\mathrm{Ir}_{1} / \mathrm{NFS}$ possesses a better activity with the significantly lower limiting potential of $1.50 \mathrm{~V}$ versus CHE. This result implies that the replacement of the substrate from oxide to sulfide can efficiently reduce the limiting potential and greatly enhance OER activity. As shown in Supplementary Figs. 43 and 44, the additional theoretical analysis of the NFS without Ir SAC emphasizes that the Ir SAC is the main factor for the exceptional alkaline OER catalysis of the $\operatorname{Ir}_{1} / \mathrm{NFS}$.

Then we calculated the electronic properties of Ir atoms on different substrates to get more deep insights into the effect of substrate on the OER catalytic performance. To get more deep insights into the effect of substrate on the OER catalytic performance, we calculated the electronic properties of Ir atoms on different substrates. The total density of states (TDOS) (Supplementary Fig. 45) shows that $\operatorname{Ir}_{1} / \mathrm{NFS}$ has more electronic states near the Fermi level compared to $\operatorname{Ir}_{1} / \mathrm{NFH}$, resulting in higher electrical conductivity, which is consistent with the results of resistance test. As the active site for adsorbing different intermediates, the electronic properties of the $4 d$ orbitals of the Ir atom are of concern to us. The projected density of states (PDOS) results (Supplementary Figs. 46 and 47) suggest that the electrons on $\mathrm{Ir}$ atoms in $\mathrm{Ir}_{1} / \mathrm{NFS}$ are closer to the Fermi level, and tend to be delocalized throughout the reaction compared with $\operatorname{Ir}_{1} / \mathrm{NFH}$, which contributes to the enhanced electrochemical performance because of the elevated electron transfer.

Furthermore, the differential charge density of the surface of $\operatorname{Ir}_{1} /$ NFS and $\operatorname{Ir}_{1} / \mathrm{NFH}$ was adopted to rationalize the OER activity difference observed in the experiments. Combined with Bader charge analysis ${ }^{52,53}$, we have thoroughly studied the charge transfer between Ir atoms and different intermediates (Fig. 4e, f, and Supplementary Table 8). Compared with oxide substrates, Ir atoms on sulfide substrates tend to lose fewer electrons and exhibit a lower valence, which leads to the relatively weaker coupling of Ir atoms and oxygen-containing intermediates (Supplementary Table 9). There is still a linear relationship between the adsorption Gibbs free energy of intermediates ${ }^{*} \mathrm{O}$ and ${ }^{*} \mathrm{OOH}$ on $\operatorname{Ir}_{1} / \mathrm{NFS}(2.90 \mathrm{eV})$ and $\mathrm{Ir}_{1} / \mathrm{NFH}(2.86 \mathrm{eV})$. Charge transfer from substrate to form ${ }^{*} \mathrm{O} / \mathrm{Ir}_{1}$ from $* \mathrm{OH} / \mathrm{Ir}_{1}$ and the back transfer from $* \mathrm{O} / \mathrm{Ir}_{1}$ to form $* \mathrm{OOH} / \mathrm{Ir}_{1}$ is closer to each on $\operatorname{Ir}_{1} / \mathrm{NFS}$ than $\operatorname{Ir}_{1} / \mathrm{NFH}$, which indicates that the replacement of the substrates is just conducive to the equal distribution of the reaction Gibbs free energies of the transfer from ${ }^{*} \mathrm{OH}$ to ${ }^{*} \mathrm{O}$ and ${ }^{*} \mathrm{O}$ to ${ }^{*} \mathrm{OOH}$ and lowers the rate-limiting potential. Meanwhile, we considered the oxidation of the substrate near iridium atoms to simulate the influence of the oxidizing environment (Supplementary Figs. 48 and 49). According to our results, the theoretical overpotential increased to varying degrees according to the number of oxygen atoms replaced. Comparing these overpotentials, conclusion can be drawn that the excellent catalytic activity exhibited by $\operatorname{Ir}_{1} / \mathrm{NFS}$ is closely related to the loading of iridium atoms on sulfur atoms. The oxidation of the substrate may destroy the chemical environment around the iridium atoms, which on the other hand demonstrates the superiority of the sulfide substrate. Therefore, both theoretical and experimental results are in agreement that the OER performance could be increased by dispersing Ir on NFS support with strong synergetic coupling which significantly enhanced intrinsic electrocatalytic activity and stability.

\section{Discussion}

In summary, the $\operatorname{Ir}_{1}$ /NFS was synthesized via a general strategy to anchor a low mass loading but high distribution density Ir singleatom sites on the NFS support by a two-step electrochemical method. Compared with $\operatorname{Ir}_{1} / \mathrm{NFH}, \mathrm{Ir}_{1} / \mathrm{NFS}$ reveals an excellent OER performance in alkaline electrolyte. Based on DFT calculations, the superior activity could be attributed to the Ir-S moiety in $\mathrm{Ir}_{1} / \mathrm{NFS}$, manifested in favorable formation of the ${ }^{*} \mathrm{OOH}$ intermediate in the OER process. Meanwhile, the weak interaction between isolated Ir atoms and NFS is optimal to proceed OER compared with that $\mathrm{Ir}-\mathrm{O}-\mathrm{M}$ bond in $\mathrm{Ir}_{1} / \mathrm{NFH}$, avoiding formation of the high oxidation state of $\mathrm{Ir}$ in $\operatorname{Ir}_{1} / \mathrm{NFS}$. This work can help us understand the interaction of the sulfide substrate and precious metal single-atom catalysts for water oxidation, which may also inspire further work in catalyst design in the broad high concentration and stability of single atomic catalysis area.

\section{Methods}

Synthesis of $\mathbf{I r}_{\mathbf{1}} / \mathbf{N F S}$. Ni foam (NF, thickness: $0.5 \mathrm{~mm}$ ) was sonicated in $5.0 \mathrm{M}$ $\mathrm{HCl}$ solution to remove surface oxide layer. Then, the $\mathrm{Ni}$ foam was washed with water and acetone, subsequently, dried at $40^{\circ} \mathrm{C}$ under vacuum as electrode. $\mathrm{Ni}$ modified gold electrode $\left(\mathrm{Ni} / \mathrm{Au}_{\text {disc }}\right)$ was prepared by electrodeposition on $\mathrm{Au}$ electrode $(\phi=5 \mathrm{~mm})$ in electrolyte containing $1.0 \mathrm{M} \mathrm{NiSO}_{4} \cdot 6 \mathrm{H}_{2} \mathrm{O}$ and $2.0 \mathrm{M}$ Orthoboric acid at $60^{\circ} \mathrm{C}$. The current density of the prepared $\mathrm{Ni} / \mathrm{Au}_{\mathrm{disc}}$ is $2.5 \mathrm{~mA} \mathrm{~cm}^{-2}$ for $1000 \mathrm{~s}$ under $600 \mathrm{rpm}$.

A standard three-electrode electrochemical cell was used as the electrodeposition device which containing $\mathrm{Ni}$ foam and $\mathrm{Ni} / \mathrm{Au}_{\text {disc }}$ as the working electrodes, a carbon rod as the counter electrode and a $\mathrm{Hg} / \mathrm{HgO}$ electrode $(1.0 \mathrm{M} \mathrm{KOH})$ as the reference electrode. $\mathrm{Ir}_{1} / \mathrm{NFS}$ electrode was prepared by a two-step electrodeposition method. The electrolyte was composed of $3 \mathrm{mM} \mathrm{Ni}\left(\mathrm{NO}_{3}\right)_{2} \cdot 6 \mathrm{H}_{2} \mathrm{O}, 3 \mathrm{mM} \mathrm{Fe}\left(\mathrm{NO}_{3}\right)_{3} \cdot 9 \mathrm{H}_{2} \mathrm{O}$ and $3 \mathrm{mM}$ thiourea. The cyclic voltammetry $(\mathrm{CV})$ was carried out in the potential range from $0.2 \mathrm{~V}$ to $-1.2 \mathrm{~V}$ versus $\mathrm{Hg} / \mathrm{HgO}$ at $5 \mathrm{mV} \mathrm{s}^{-1}$ for three cycles to get the NFS substrate. Then, $0.05 \mathrm{mM}$ precursor $\left(\mathrm{IrCl}_{3} \cdot \mathrm{xH}_{2} \mathrm{O}\right)$ was added to the electrolyte and the potential range was changed to $0.3 \mathrm{~V}$ to $-0.3 \mathrm{~V}$ versus $\mathrm{Hg} / \mathrm{HgO}$ at $50 \mathrm{mV} \cdot \mathrm{s}^{-1}$ for 15 cycles to get the $\operatorname{Ir}_{1} / \mathrm{NFS}$. Besides Ni foam electrode, $\operatorname{Ir}_{1} / \mathrm{NFS}$ catalyst was also electrodeposited on $\mathrm{Ni} / \mathrm{Au}_{\text {disc }}$ following the same procedures.

To verify the role of sulfide substrate, the $\mathrm{Ir}_{1} / \mathrm{Ni}_{\mathrm{y}} \mathrm{Fe}_{(6-\mathrm{y})} \mathrm{S}_{\mathrm{x}}(\mathrm{y}=0-6)$ electrodes with a variable $\mathrm{Ni} / \mathrm{Fe}$ ratio were prepared by adjusting the $\mathrm{Ni}$ and $\mathrm{Fe}$ ions concentration in the electrodeposited electrolytes. The electrodeposition was followed by the same procedures as the $\mathrm{Ir}_{1} / \mathrm{NFS}$ electrode fabrication.

Synthesis of $\mathbf{M}_{\mathbf{1}} / \mathbf{N F S}(\mathbf{M}=\mathbf{P t}, \mathbf{A u}, \mathbf{R u})$. For the synthesis of $\mathrm{Pt}_{1} / \mathrm{NFS}, \mathrm{Au}_{1} / \mathrm{NFS}$ and $\mathrm{Ru}_{1} / \mathrm{NFS}$, the precious precursors $\left(\mathrm{H}_{2} \mathrm{PtCl}_{6} \cdot 6 \mathrm{H}_{2} \mathrm{O}, \mathrm{HAuCl}_{4} \cdot 4 \mathrm{H}_{2} \mathrm{O}\right.$, and $\mathrm{RuCl}_{3} \cdot \mathrm{xH}_{2} \mathrm{O}$ ) replaced $\mathrm{IrCl}_{3} \cdot \mathrm{xH}_{2} \mathrm{O}$ in the electrolyte, respectively. The electrodeposition procedures were the same as these for the synthesis of $\operatorname{Ir}_{1} / \mathrm{NFS}$.

Synthesis of $\mathbf{I r}_{\mathbf{1}} / \mathbf{N F H}$. For the synthesis of $\operatorname{Ir}_{1} / \mathrm{NFH}$, thiourea was removed from the electrolyte and the electrodeposition procedures were the same as these for the synthesis of $\operatorname{Ir}_{1} / \mathrm{NFS}$. 
a

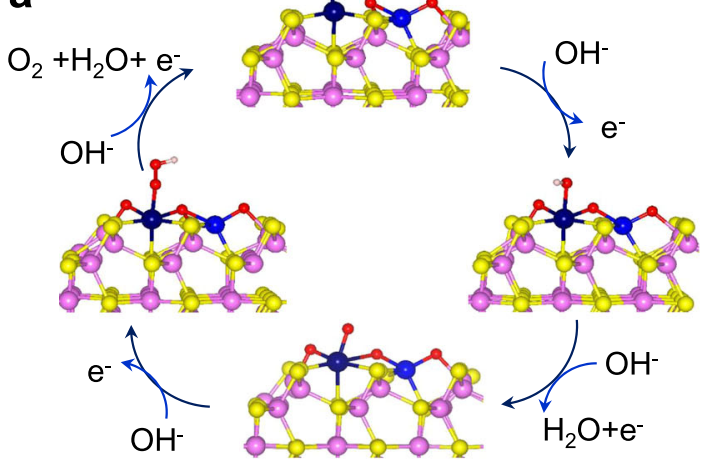

C

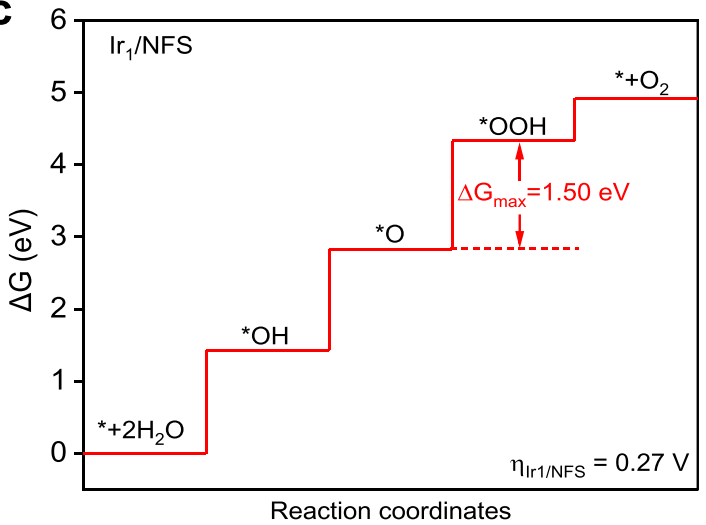

e

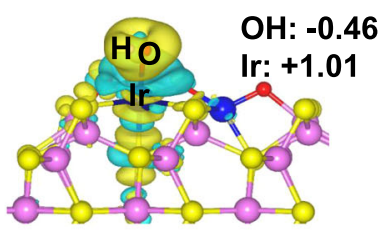

$\mathbf{f}$

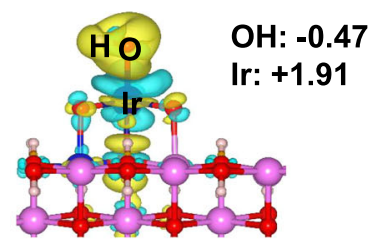

b
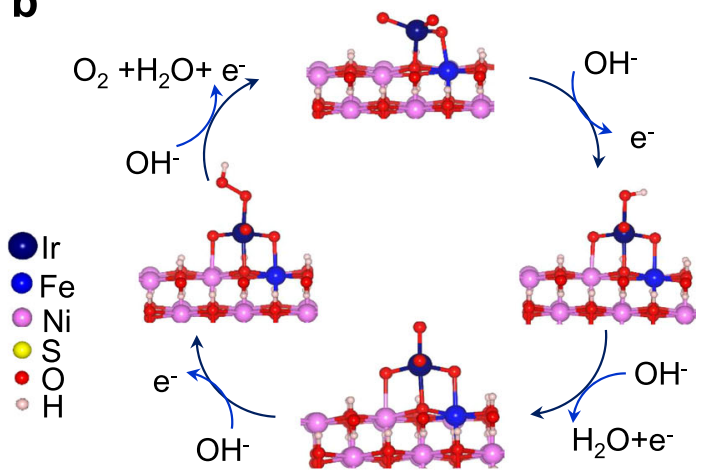

d

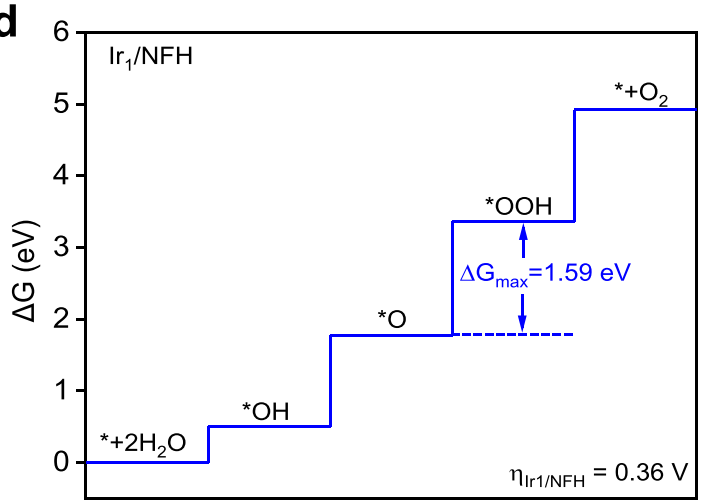

Reaction coordinates
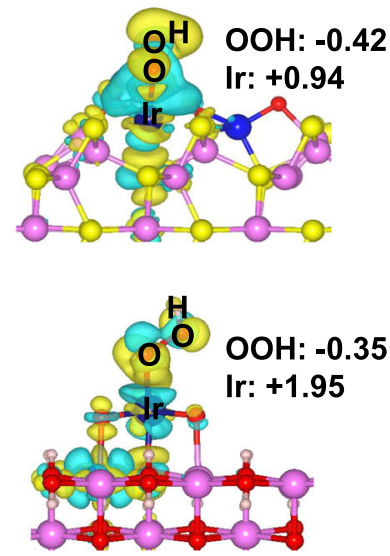

Fig. 4 DFT theoretical models. a, b Proposed $4 \mathrm{e}^{-}$mechanism of oxygen evolution reaction on $\operatorname{Ir}_{1} / \mathrm{NFS}$ and $\operatorname{Ir}_{1} / \mathrm{NFH}$. c, $\mathbf{d}$ The free energy profiles of fourstep elementary reaction on $\mathrm{Ir}_{1} / \mathrm{NFS}$ and $\mathrm{Ir}_{1} / \mathrm{NFH}$. e, $\mathbf{f}$ Diagrams of charge transfer between oxygen-containing intermediates and $\mathrm{Ir}$ atom during the oxygen evolution reaction of $(\mathbf{e}) \operatorname{Ir}_{1} / \mathrm{NFS}$ and $(\mathbf{f}) \operatorname{Ir}_{1} / \mathrm{NFH}$. Green area represents the loss of electrons, while yellow area represents the opposite.

Prepared the $\mathrm{Ir} / \mathrm{C}$ and $\mathrm{IrO} \mathrm{O}_{2}$ electrodes. To prepare the $\mathrm{Ir} / \mathrm{C}$ ink, $11 \mathrm{mg}$ of $\mathrm{Ir} / \mathrm{C}$ (5 wt\% of Ir, Premetek Co.) was dispersed in $1 \mathrm{ml}$ of water and ethanol solution $(1: 4, v / v)$, followed by the addition of $45 \mu \mathrm{l}$ of Nafion 117 solution (Sigma-Aldrich). The mixture was then magnetic stirred to form a homogenous ink. Meanwhile, the $\mathrm{IrO}_{2}$ ink was also prepared, namely $5.14 \mathrm{mg}$ of $\mathrm{IrO}_{2}$ and $5 \mathrm{mg}$ of Ketjen Black dispersed in $1 \mathrm{ml}$ of water and ethanol solution $(1: 4, \mathrm{v} / \mathrm{v})$, followed by the addition of $40 \mu \mathrm{l}$ of Nafion 117 solution (Sigma-Aldrich). The mixture was then sonicated briefly to form a homogenous ink. The ink was drop-casted onto the Ni foam and $\mathrm{Ni} / \mathrm{Au}_{\text {disc }}$ electrodes and left dried in air.

Characterizations. The morphologies and structures of as-prepared samples were characterized by field-emission scanning electron microscopy (SEM, Hitachi, SU8010, $10 \mathrm{kV}$ ) and transmission electron microscopy (TEM, Hitachi, H7700, $100 \mathrm{kV}$ ). HAADF-STEM images, and energy-dispersive X-ray (EDX) mappings were obtained by using a JEOL, JEM $-2100,200 \mathrm{kV}$. X-ray diffraction (XRD) patterns were measured by using a Bruker D8 Advance X-ray diffractometer equipped with $\mathrm{Cu} \mathrm{Ka}$ radiation $(\lambda=1.5418 \AA$ ). X-ray photoelectron spectra (XPS) were performed by using a Thermo Scientific ESCALAB 250Xi with monochromatic Al Ka X-ray sources $(1486.6 \mathrm{eV})$ at $2.0 \mathrm{kV}$ and $20 \mathrm{~mA}$. Inductively coupled plasma mass spectrometer (ICP-MS) was performed on iCAP 7400. Raman spectra was carried out on a Renishaw RM 3000 Micro-Raman system.

Electrochemical characterization. All electrochemical measurements were carried out with a three-electrode on the $\mathrm{CHI} 760 \mathrm{E}$ electrochemical workstation. Asprepared $\mathrm{Ir}_{1} / \mathrm{NFS}$ and $\mathrm{Ir}_{1} / \mathrm{NFH}$ electrodeposited on $\mathrm{Ni}$ foam $(1 \mathrm{~cm} \times 1 \mathrm{~cm})$ and $\mathrm{Ni} /$ $\mathrm{Au}_{\text {disc }}$ electrodes were used directly as the working electrode without any further treatments. A carbon rod was used as the counter electrode and a $\mathrm{Hg} / \mathrm{HgO}$ electrode $(1.0 \mathrm{M} \mathrm{KOH})$ was used as the reference electrode in $1.0 \mathrm{M} \mathrm{KOH}$ solution. All potential values in electrochemical measurements were calibrated with respect to the reversible hydrogen electrode (RHE). The calibration was performed in the high purity hydrogen $1.0 \mathrm{M} \mathrm{KOH}$ electrolyte with a Pt wire as the working electrode and a carbon rod as the counter electrode. The measured potentials versus $\mathrm{Hg} / \mathrm{HgO}$ were converted to the values with reference to a RHE using the following equation ${ }^{54}$

$$
E_{R H E}=E_{\mathrm{Hg} / \mathrm{HgO}}+0.197 \mathrm{~V}
$$

Catalytic activity was assessed by linear sweep voltammetry (LSV) with a sweep rate of $5 \mathrm{mV} \cdot \mathrm{s}^{-1}$ with $95 \% i R$ compensation. Tafel slopes were derived from the 
OER polarization curves obtained at $5 \mathrm{mV} \cdot \mathrm{s}^{-1}$. For $i R$ compensation, an $i R$ compensation level of $95 \%$ was applied by using the automated $i R$-correction function of the potentiostat ${ }^{55}$. Electrochemical impedance spectroscopy (EIS) curves were recorded under amplitude $5 \mathrm{mV}$, and the frequency ranged from $10 \mathrm{~K} \mathrm{~Hz}$ to $0.1 \mathrm{~Hz}$ at an overpotential of $250 \mathrm{mV}$. The Double-layer capacitance $\left(\mathrm{C}_{\mathrm{dl}}\right)$ was determined by measuring the capacitive current associated with doublelayer at non-Faradaic potential range charging from the scan-rate dependence of $\mathrm{CV}^{43} \cdot \mathrm{C}_{\mathrm{dl}}$ was estimated by plotting the half of the difference of the anodic and cathodic current density against the scan rate. All chronopotentiometry and chronoamperometry measurements were conducted under the same experimental setup without $i R$ compensation.

Overall water splitting test condition: a two-electrode electrolysis device was fabricated by using $\mathrm{Ir}_{1}$ /NFS as the OER catalyst and $\mathrm{NiFe}-\mathrm{OH}-\mathrm{PO}_{4}$ as hydrogen evolution catalyst in $1.0 \mathrm{M} \mathrm{KOH}$ solution. The $\mathrm{NiFe}-\mathrm{OH}-\mathrm{PO}_{4}$ was electrodeposited onto the Ni foam by $\mathrm{CV}$ in electrolyte containing $3.0 \mathrm{mM} \mathrm{NiCl} \cdot 6 \mathrm{H}_{2} \mathrm{O}, 3.0 \mathrm{mM}$ $\mathrm{FeCl}_{2} \cdot 4 \mathrm{H}_{2} \mathrm{O}$, and $1.0 \mathrm{mM} \mathrm{NaH} \mathrm{PO}_{2}$. The $\mathrm{CV}$ curves were carried out in the potential range from $0.2 \mathrm{~V}$ to $-1.2 \mathrm{~V}$ versus $\mathrm{Hg} / \mathrm{HgO}$ at $5 \mathrm{mV} \mathrm{s}^{-1}$ for three cycles to get the $\mathrm{NiFe}-\mathrm{OH}-\mathrm{PO}_{4}$ catalyst. Subsequently, the $\mathrm{Ir}_{1} / \mathrm{NFS}$ and $\mathrm{NiFe}-\mathrm{OH}-\mathrm{PO}_{4}$ catalysts were assembled into a two-electrode system, and the electrodes area were $2 \mathrm{~cm} \times 2 \mathrm{~cm}$, respectively. The overall water splitting was driven by a single-cell AAA battery with a nominal voltage of $\sim 1.5 \mathrm{~V}$ in $1.0 \mathrm{M} \mathrm{KOH}$.

Calculation of turnover frequency (TOF). The TOF values of $\operatorname{Ir}_{1} / \mathrm{NFS}$, and $\operatorname{Ir}_{1} /$ $\mathrm{NFH}$ coated on $\mathrm{Ni} / \mathrm{Au}_{\text {disc }}$ were calculated according to the equation ${ }^{56}$,

$$
T O F=j \times \frac{A}{4 \times F \times m}
$$

where $j$ is the current density obtained at overpotential of $300 \mathrm{mV}$ in $\mathrm{A} \mathrm{cm}^{-2}$, and the contribution of the $\mathrm{Ni}$ and Fe active sites to the current density is deducted. A is the surface area of the $\mathrm{Ni} / \mathrm{Au}_{\text {disc }}$ electrode $\left(0.19625 \mathrm{~cm}^{2}\right), \mathrm{F}$ is the Faraday efficiency $\left(96,485 \mathrm{C} \mathrm{mol}^{-1}\right)$ and $\mathrm{m}$ is the number of moles of the Ir deposited onto the $\mathrm{Ni}$ / $\mathrm{Au}_{\text {disc }}$ electrode which was calculated by ICP-MS measurement.

Theoretical calculations. In this study, all the spin-polarized calculations were performed by using the Vienna Ab-initio Simulation Package (VASP) with the projector augmented wave method for the core region and a plane-wave kinetic energy cutoff of $400 \mathrm{eV}^{57-59}$. The DFT $+\mathrm{U}$ calculations were performed in calculating the nickel oxide system, while the value of $\mathrm{U}$ was 4.3 for $\mathrm{Fe}$ and 3.8 for $\mathrm{Ni}$ according to the previous studies ${ }^{60}$. The generalized gradient approximation method with Perdew-Burke-Ernzerh of (PBE) functional for the exchange-correlation term was used ${ }^{61}$. The models we adopted for calculation were modified from the surface of $\mathrm{Ni}_{3} \mathrm{~S}_{2}(003)^{62}$ and $\mathrm{Ni}(\mathrm{OH})_{2}$ (012), which are based on XRD and SADE results. After replacing the $\mathrm{Ni}$ atom with a Fe atom at the outermost layer, an Ir atom was loaded on $\mathrm{S}$ atoms or $\mathrm{O}$ atoms near it. In order to simulate the environment where oxygen is enriched on the electrode surface in actual electrocatalytic process, both Ir and $\mathrm{Fe}$ atoms have been highly coordinated by $\mathrm{O}$ atoms as shown in Fig. $4 \mathrm{a}$ and Supplementary Fig. 42. $\mathrm{Ir}_{1} / \mathrm{NFS}$ model used in our calculation consists of $12.21 \AA \times 12.21 \AA \times 25.18 \AA$ and $\operatorname{Ir}_{1} / \mathrm{NFH}$ consists of

$9.31 \AA \times 1.93 \AA \times 22.06 \AA$. The large vacuum region was set at least $15 \AA$ in $z$ direction for the isolation of surface to prevent the interaction between two periodic units. A $3 \times 3 \times 1$ Monkhorst-Pack sampled k-point grid was used to sample the reciprocal space. For the structure optimization, the convergence of energy and forces on each atom were set to be less than $1 \times 10^{-5} \mathrm{eV}$ and $0.02 \mathrm{eV} / \mathrm{A}$. During our calculation, top two layers were fully relaxed and the other layers are fixed at the lattice positions.

According to the OER cycle proposed by Nørskov ${ }^{49}$, the OER reaction follows the four-electron mechanism, corresponding to the four primitive steps listed in Eqs. (3) to (6), which involve adsorbed $\mathrm{OH}, \mathrm{O}$, and $\mathrm{OOH}$ intermediates on the surface $(*)$,

$$
\begin{gathered}
*+\mathrm{OH}^{-} \rightarrow{ }^{*} \mathrm{OH}+\mathrm{e}^{-} \\
{ }^{*} \mathrm{OH}+\mathrm{OH}^{-} \rightarrow \mathrm{H}_{2} \mathrm{O}+{ }^{*} \mathrm{O}+\mathrm{e}^{-} \\
{ }^{*} \mathrm{O}+\mathrm{OH}^{-} \rightarrow{ }^{*} \mathrm{OOH}+\mathrm{e}^{-} \\
{ }^{*} \mathrm{OOH}+\mathrm{OH}^{-} \rightarrow \mathrm{O}_{2}+\mathrm{H}_{2} \mathrm{O}+\mathrm{e}^{-}
\end{gathered}
$$

The Gibbs free energy changes for these four elemental steps can be expressed respectively as ${ }^{48}$,

$$
\begin{gathered}
\Delta \mathrm{G}_{1}=\mu_{* \mathrm{OH}}-\mu_{*}-\left(\mu_{\mathrm{OH}^{-}}-\mu_{e^{-}}\right) \\
\Delta \mathrm{G}_{2}=\mu_{* \mathrm{O}}-\mu_{* \mathrm{OH}}+\mu_{\mathrm{H}_{2} \mathrm{O}(l)}-\left(\mu_{\mathrm{OH}^{-}}-\mu_{e^{-}}\right) \\
\Delta \mathrm{G}_{3}=\mu_{* \mathrm{OOH}}-\mu_{*_{\mathrm{O}}}-\left(\mu_{\mathrm{OH}^{-}}-\mu_{e^{-}}\right) \\
\Delta \mathrm{G}_{4}=\mu_{*}+\mu_{\mathrm{H}_{2} \mathrm{O}(l)}+\mu_{\mathrm{O}_{2}(g)}-\mu_{* \mathrm{OOH}}-\left(\mu_{\mathrm{OH}^{-}}-\mu_{e^{-}}\right)
\end{gathered}
$$

Here, the difference of the chemical potentials of the $\mathrm{OH}^{-}$species and the electron can be described as,

$$
\mu_{\mathrm{OH}^{-}}-\mu_{e^{-}}=\mu_{\mathrm{H}_{2} \mathrm{O}(l)}-\left(\mu_{\mathrm{H}^{+}}+\mu_{e^{-}}\right)
$$

Meanwhile, the chemical potential of the proton and electron is related to that of $\mathrm{H}_{2}$ according to the computational hydrogen electrode $(\mathrm{CHE})$ approach.

$$
\mu_{H^{+}}+\mu_{e^{-}}=\frac{1}{2} \mu_{H_{2}(g)}-e U_{R H E}
$$

where $U_{R H E}$ was the potential of the electrode relative to the RHE. Thus, Eqs. (13)-(16) can be rewritten as,

$$
\begin{gathered}
\Delta \mathrm{G}_{1}=\mu_{*_{\mathrm{OH}}}-\mu_{*}-\mu_{\mathrm{H}_{2} \mathrm{O}(l)}+\frac{1}{2} \mu_{\mathrm{H}_{2}(g)}-e U_{R H E} \\
\Delta \mathrm{G}_{2}=\mu_{*_{\mathrm{O}}}-\mu_{*_{\mathrm{OH}}}-\mu_{\mathrm{H}_{2} \mathrm{O}(l)}+\frac{1}{2} \mu_{\mathrm{H}_{2}(g)}-e U_{R H E} \\
\Delta \mathrm{G}_{3}=\mu_{*_{\mathrm{OOH}}}-\mu_{*_{\mathrm{O}}}-\mu_{\mathrm{H}_{2} \mathrm{O}(l)}+\frac{1}{2} \mu_{\mathrm{H}_{2}(g)}-e U_{R H E} \\
\Delta \mathrm{G}_{4}=\mu_{*}-\mu_{*_{\mathrm{OOH}}}+\mu_{\mathrm{O}_{2}(g)}+\frac{1}{2} \mu_{\mathrm{H}_{2}(g)}-e U_{R H E}
\end{gathered}
$$

The chemical potential $\mu$ was defined as ${ }^{63} \mu=E+Z P E-T \times S$, where $E, Z P E$, $T$, and $S$ represented the total energy obtained from DFT calculations, the zeropoint energy $(Z P E)$, the temperature $(298.15 \mathrm{~K})$, the entropy obtained from vibrational frequency calculations, respectively.

The entropies of gas-phase $\mathrm{H}_{2}$, and $\mathrm{H}_{2} \mathrm{O}$ were obtained from the NIST database (Computational Chemistry Comparison and Benchmark Database. http://cccbdb.nist.gov/) with standard condition. Due to the non-negligible error in the first-principles calculation, the chemical potential of oxygen molecule is calculated as $\mu_{\mathrm{O}_{2}}=2 G_{\mathrm{H}_{2} \mathrm{O}(l)}-2 G_{\mathrm{H}_{2}}+4.92 \mathrm{eV}$. Then entropies of adsorbed species are considered according to vibrational entropy $\left(S_{v}\right)$ formula,

$$
S_{v}=\sum_{i} R\left\{\frac{h v_{i}}{k_{B} T}\left[\exp \left(\frac{h v_{i}}{k_{B} T}\right)-1\right]^{-1}-\ln \left[1-\exp \left(-\frac{h v_{i}}{k_{B} T}\right)\right]\right\}
$$

All the real vibrational frequencies of the surface-adsorbing species were included to calculate the correction of the free energy.

Under ideal conditions, the OER reaction with a total energy change of $4.92 \mathrm{eV}$ can be driven at $1.23 \mathrm{~V}$, while the $\triangle G$ of each elementary reaction would be equally divided into $1.23 \mathrm{eV}$. Therefore, the overpotential $\eta$ is introduced to represent additional required potential and measure the catalytic activity of materials, which is defined in theoretical calculations as,

$$
\eta=\frac{\max \left[\Delta \mathrm{G}_{1}, \Delta \mathrm{G}_{2}, \Delta \mathrm{G}_{3}, \Delta \mathrm{G}_{4}\right]}{e}-1.23 \mathrm{~V}
$$

\section{Data availability}

All the data supporting this study in the paper and Supplementary Information can be accessed using the link https://doi.org/10.6084/m9.figshare.17073017.v1. Source data are provided with this paper.

Received: 7 April 2021; Accepted: 1 December 2021; Published online: 10 January 2022

\section{References}

1. Chen, S., Takata, T. \& Domen, K. Particulate photocatalysts for overall water splitting. Nat. Rev. Mater. 2, 17050 (2017)

2. Seh, Z. W. et al. Combining theory and experiment in electrocatalysis: insights into materials design. Science 355, eaad4998 (2017).

3. Liu, C. et al. Water splitting-biosynthetic system with $\mathrm{CO} 2$ reduction efficiencies exceeding photosynthesis. Science 352, 1210-1213 (2017)

4. Jiao, Y., Zheng, Y., Jaroniec, M. \& Qiao, S. Z. Design of electrocatalysts for oxygen- and hydrogen-involving energy conversion reactions. Chem. Soc. Rev. 44, 2060-2086 (2015)

5. Song, J. et al. A review on fundamentals for designing oxygen evolution electrocatalysts. Chem. Soc. Rev. 49, 2196-2214 (2020).

6. Xiao, H., Shin, H. \& Goddard, W. A. III Synergy between Fe and $\mathrm{Ni}$ in the optimal performance of $(\mathrm{Ni}, \mathrm{Fe}) \mathrm{OOH}$ catalysts for the oxygen evolution reaction. Proc. Natl Acad. Sci. U. S. A. 115, 5872-5877 (2018).

7. Zhang, B. et al. Homogeneously dispersed multimetal oxygen-evolving catalysts. Science 352, 333-337 (2016).

8. Lei, Z. W. et al. Recent progress in electrocatalysts for acidic water oxidation. Adv. Energy Mater. 10, 2000478 (2020). 
9. Liu, Y. P. et al. Corrosion engineering towards efficient oxygen evolution electrodes with stable catalytic activity for over 6000 hours. Nat. Commun. 9, 2609 (2018).

10. Song, J. J. et al. A review on fundamentals for designing oxygen evolution electrocatalysts. Chem. Soc. Rev. 49, 2196 (2020).

11. Shi, Q., Zhu, C., Du, D. \& Lin, Y. Robust noble metal-based electrocatalysts for oxygen evolution reaction. Chem. Soc. Rev. 48, 3181-3192 (2019).

12. Pérez-Ramírez, J. \& López, N. Strategies to break linear scaling relationships. Nat. Catal. 2, 971-976 (2019).

13. Zhu, J., Hu, L., Zhao, P., Lee, L. Y. S. \& Wong, K.-Y. Recent advances in electrocatalytic hydrogen evolution using nanoparticles. Chem. Rev. 120, 851-918 (2020).

14. Zhang, B. et al. High-valence metals improve oxygen evolution reaction performance by modulating $3 \mathrm{~d}$ metal oxidation cycle energetics. Nat. Catal. 3, 985-992 (2020).

15. Guerra, O. J., Eichman, J., Kurtz, J. \& Hodge, B.-M. Cost competitiveness of electrolytic hydrogen. Joule 3, 2425-2443 (2019).

16. Fei, H. et al. Single atom electrocatalysts supported on graphene or graphenelike carbons. Chem. Soc. Rev. 48, 5207-5241 (2019).

17. Kaiser, S. K., Chen, Z., Faust Akl, D., Mitchell, S. \& Perez-Ramirez, J. Singleatom catalysts across the periodic table. Chem. Rev. 120, 11703-11809 (2020).

18. Wang, A., Li, J. \& Zhang, T. Heterogeneous single-atom catalysis. Nat. Rev. Chem. 2, 65-81 (2018).

19. Gawande, M. B., Fornasiero, P. \& Zbořil, R. Carbon-based single-atom catalysts for advanced applications. ACS Catal. 10, 2231-2259 (2020).

20. Shao, X. et al. Iridium single-atom catalyst performing a quasi-homogeneous hydrogenation transformation of CO2 to formate. Chem 5, 693-705 (2019).

21. Sharma, P. et al. Carbon nitride-based ruthenium single atom photocatalyst for CO2 reduction to methanol. Small 17, 2006478 (2021).

22. Gusmao, R., Vesely, M. \& Sofer, Z. Recent developments on the single atom supported at 2D materials beyond graphene as catalysts. ACS Catal. 10, 9634-9648 (2020).

23. Zhao, D. et al. Atomic site electrocatalysts for water splitting, oxygen reduction and selective oxidation. Chem. Soc. Rev. 49, 2215-2264 (2020).

24. Wang, D. W. et al. Atomic and electronic modulation of self-supported nickelvanadium layered double hydroxide to accelerate water splitting kinetics. Nat. Commun. 10, 3899 (2019).

25. Singh, B. et al. Single-atom catalysts: a sustainable pathway for the advanced catalytic applications. Small 17, 2006473 (2021).

26. Yao, Y. C. et al. Engineering the electronic structure of single atom Ru sites via compressive strain boosts acidic water oxidation electrocatalysis. Nat. Catal. 2, 304-313 (2019).

27. Kibsgaard, J. \& Chorkendorff, I. Considerations for the scaling-up of water splitting catalysts. Nat. Energy 4, 430-433 (2019).

28. Qi, K., Chhowalla, M. \& Voiry, D. Single atom is not alone: metal-support interactions in single-atom catalysis. Mater. Today 40, 173-192 (2020).

29. Ji, S. F. et al. Chemical synthesis of single atomic site catalysts. Chem. Rev. 120, 11900-11955 (2020).

30. Mitchell, S. \& Pérez-Ramírez, J. Single atom catalysis: a decade of stunning progress and the promise for a bright future. Nat. Commun. 11, 4302 (2020).

31. Wang, Q. et al. Ultrahigh-loading of Ir single atoms on $\mathrm{NiO}$ matrix to dramatically enhance oxygen evolution reaction. J. Am. Chem. Soc. 142, 7425-7433 (2020).

32. Lai, W. H. et al. General $\pi$-electron-assisted strategy for Ir, Pt, Ru, Pd, Fe, Ni single-atom electrocatalysts with bifunctional active sites for highly efficient water splitting. Angew. Chem. Int. Ed. Engl. 58, 11868-11873 (2019).

33. Zhang, $Z$. et al. Electrochemical deposition as a universal route for fabricating single-atom catalysts. Nat. Commun. 11, 1215 (2020).

34. Zhang, J. F. et al. Single-atom Au/NiFe layered double hydroxide electrocatalyst: probing the origin of activity for oxygen evolution reaction. J. Am. Chem. Soc. 140, 3876-3879 (2018).

35. Li, P. S. et al. Boosting oxygen evolution of single-atomic ruthenium through electronic coupling with cobalt-iron layered double hydroxides. Nat. Commun. 10, 1711 (2019).

36. Wang, Y. X. et al. Advanced electrocatalysts with single-metal-atom active sites. Chem. Rev. 120, 12217-12314 (2020).

37. Sun, T. et al. Design of local atomic environments in single-atom electrocatalysts for renewable energy conversions. Adv. Mater. 33, 2003075 (2020).

38. Liu, L. \& Corma, A. Metal catalysts for heterogeneous catalysis: from single atoms to nanoclusters and nanoparticles. Chem. Rev. 118, 4981-5079 (2018).

39. Liu, L. C. \& Corma, A. Confining isolated atoms and clusters in crystalline porous materials for catalysis. Nat. Rev. Mater. 6, 244-263 (2020).

40. Kaiser, S. K. et al. Design of carbon supports for metal-catalyzed acetylene hydrochlorination. Nat. Commun. 12, 4016 (2021).

41. Cao, P. G., Yao, J. L., Bin, R., Gu, R. N. \& Tian, Z. Q. Surface-enhanced Raman scattering spectra of thiourea adsorbed at an iron electrode in NaClO4 solution. J. Phys. Chem. B 106, 10150-10156 (2002).
42. Wei, C. et al. Approaches for measuring the surface areas of metal oxide electrocatalysts for determining their intrinsic electrocatalytic activity. Chem. Soc. Rev. 48, 2518-2534 (2019).

43. McCrory, C. C. L., Jung, S., Peters, J. C. \& Jaramillo, T. F. Benchmarking heterogeneous electrocatalysts for the oxygen evolution reaction. J. Am. Chem. Soc. 135, 16977-16987 (2013).

44. Lei, Z. W., Bai, J. J., Li, Y. B., Wang, Z. L. \& Zhao, C. Fabrication of nanoporous nickel-iron hydroxylphosphate composite as bifunctional and reversible catalyst for highly efficient intermittent water splitting. ACS Appl. Mater. Interfaces 9, 35837-35846 (2017).

45. Cao, D. F. et al. Anomalous self-optimization of sulfate ions for boosted oxygen evolution reaction. Sci. Bull. 66, 553-561 (2021).

46. Wang, T. Y. et al. NiFe (oxy) hydroxides derived from NiFe disulfides as an efficient oxygen evolution catalyst for rechargeable $\mathrm{Zn}$-air batteries: the effect of surface S residues. Adv. Mater. 30, 1800757 (2018).

47. Shi, Y. M. et al. Unveiling the promotion of surface-adsorbed chalcogenate on the electrocatalytic oxygen evolution reaction. Angew. Chem. Int. Ed. 59, 22470-22474 (2020).

48. Rossmeisl, J., Qu, Z. W., Zhu, H., Kroes, G. J. \& Nørskov, J. K. Electrolysis of water on oxide surfaces. J. Electroanal. Chem. 607, 83-89 (2007).

49. Man, I. C. et al. Universality in oxygen evolution electrocatalysis on oxide surfaces. ChemCatChem 3, 1159-1165 (2011)

50. Huang, Z.-F. et al. Chemical and structural origin of lattice oxygen oxidation in Co-Zn oxyhydroxide oxygen evolution electrocatalysts. Nat. Energy 4, 329-338 (2019).

51. Bajdich, M., Garcia-Mota, M., Vojvodic, A., Norskov, J. K. \& Bell, A. T. Theoretical investigation of the activity of cobalt oxides for the electrochemical oxidation of water. J. Am. Chem. Soc. 135, 13521-13530 (2013).

52. Sanville, E., Kenny, S. D., Smith, R. \& Henkelman, G. Improved grid-based algorithm for Bader charge allocation. J. Comput Chem. 28, 899-908 (2007).

53. Zheng, X. B. et al. Multifunctional active-center-transferable platinum/lithium cobalt oxide heterostructured electrocatalysts towards superior water splitting. Angew. Chem. Int. Ed. 59, 14533-14540 (2020).

54. Liang, Y. Y. et al. Co3O4 nanocrystals on graphene as a synergistic catalyst for oxygen reduction reaction. Nat. Mater. 10, 780-786 (2011).

55. He, P. F. \& Faulkner, L. R. Intelligent, automatic compensation of solution resistance. Anal. Chem. 58, 517-523 (1986).

56. Aiyappa, H. B. et al. Oxygen evolution electrocatalysis of a single MOFderived composite nanoparticle on the tip of a nanoelectrode. Angew. Chem. Int. Ed. 58, 8927-8931 (2019).

57. Kresse, G. \& Joubert, D. From ultrasoft pseudopotentials to the projector augmented-wave method. Phys. Rev. B 59, 1758-1775 (1999).

58. Kresse, G. \& Furthmüller, J. Efficient iterative schemes for ab initio total-energy calculations using a plane-wave basis set. Phys. Rev. B 54, 11169-11186 (1996)

59. Kresse, G. \& Furthmüller, J. Efficiency of ab-initio total energy calculations for metals and semiconductors using a plane-wave basis set. Comput. Mater. Sci. 6, 15-50 (1996)

60. $\mathrm{Bi}, \mathrm{Y}$. M. et al. Understanding the incorporating effect of $\mathrm{Co} 2+/ \mathrm{Co} 3+$ in NiFe-layered double hydroxide for electrocatalytic oxygen evolution reaction. J. Catal. 358, 100-107 (2018).

61. Perdew, J. P., Ernzerhof, M. \& Burke, K. Rationale for mixing exact exchange with density functional approximations. J. Chem. Phys. 105, 9982-9985 (1996).

62. Zhang, B., Fu, X. L., Song, L. \& Wu, X. J. Surface selectivity of Ni3S2 toward hydrogen evolution reaction: a first-principles study. Phys. Chem. Chem. Phys. 22, 25685-25694 (2020).

63. Nørskov, J. K. et al. Origin of the overpotential for oxygen reduction at a fuelcell cathode. J. Phys. Chem. B 108, 17886-17892 (2004).

\section{Acknowledgements}

This work was supported by the National Key Research and Development Program of China (Grant No. 2017YFA0402802), the National Natural Science Foundation of China (Grant No. 21776265, 51902304, 52072358), Anhui Provincial Natural Science Foundation (Grant No. 1908085ME122), the Fundamental Research Funds for the Central Universities (Wk2060140026, WK3430000005). The authors also thank the financial support from PetroChina. The calculations were performed on the supercomputing center of the University of Science and Technology of China (USTC-SCC) and Guangzhou-SCC. The authors also thank the Hefei National Synchrotron Radiation Laboratory (NSRL) and the Shanghai Synchrotron Radiation Facility (SSRF) for XPS and XAS characterizations.

\section{Author contributions}

R.C. and Z.L. conceived the idea and directed the project. Z.L. designed the experiments. Z.L., W.C. and Y.L. carried out the experiments. K.W., Y.J. and P.Y. provided TEM, HRTEM, and EDX characterizations. X.J. and J.L. assisted the SEM and electrochemical test. S.Z. and Z.L. performed the XAS measurements. W. Z. and Y. R. conducted the DFT 
calculations. R.C. and Z.L. analyzed the data and wrote the paper. R.C., S.J. and Z.L. revised the paper. All authors discussed the results and commented on the paper.

\section{Competing interests}

The authors declare no competing interests.

\section{Additional information}

Supplementary information The online version contains supplementary material available at https://doi.org/10.1038/s41467-021-27664-z.

Correspondence and requests for materials should be addressed to Shuhong Jiao, Wenhua Zhang or Ruiguo Cao.

Peer review information Nature Communications thanks the anonymous reviewer(s) for their contribution to the peer review of this work.

Reprints and permission information is available at http://www.nature.com/reprints
Publisher's note Springer Nature remains neutral with regard to jurisdictional claims in published maps and institutional affiliations.

(c) (i) Open Access This article is licensed under a Creative Commons Attribution 4.0 International License, which permits use, sharing, adaptation, distribution and reproduction in any medium or format, as long as you give appropriate credit to the original author(s) and the source, provide a link to the Creative Commons license, and indicate if changes were made. The images or other third party material in this article are included in the article's Creative Commons license, unless indicated otherwise in a credit line to the material. If material is not included in the article's Creative Commons license and your intended use is not permitted by statutory regulation or exceeds the permitted use, you will need to obtain permission directly from the copyright holder. To view a copy of this license, visit http://creativecommons.org/ licenses/by/4.0/.

(C) The Author(s) 2022 